\section{Archaeology: Definition}

\section{Soren Blau}

Victorian Institute of Forensic Medicine/

Department of Forensic Medicine,

Monash University, Melbourne, VIC, Australia

Archaeology comes from the Greek term arkhaiologia meaning "the study of ancient things" and is defined as the study of past peoples and culture. Archaeologists develop interpretations about the past through the recovery and analysis of material culture (which may include graves, monuments, buildings, inscriptions, tools, pottery, etc.) and associated evidence (such as pollen, charcoal, residues, skeletal remains, etc.). In order to provide interpretations about the past, archaeologists must accurately recover and record all aspects of a site.

Archaeologists may study the recent (historical) or distant past and are interested in a diverse range of subjects including how humans organized their social groupings and interacted with and/or exploited the environment, living conditions, diet, health status, trade patterns, and burial choices to name a few. For this reason, archaeologists may have specific areas of expertise which could include the analysis of specific material culture (e.g., pottery), environmental samples, human and or nonhuman skeletal remains, dating techniques, and so on.

\section{Cross-References}

- Archaeological Fieldwork

- Bone Chemistry and Ancient Diet

$\checkmark$ Bones

- Buildings Archaeology

- Ceramics: Scientific Analysis

- Conservation

- Definition of Skeletal Biology

- Environmental Assessment

- Interpretation

- Material Culture

$\rightarrow$ Museums

- Plant Domesticates

- Principles of Stratification/Geoarchaeology

- Radiocarbon Dating

Recording and Sampling

$\checkmark$ Seeds

- Site Formation Processes

- Types of Analyses: Similarities and Differences According to the Context (Forensic/Archaeological) 